\title{
MOVIMENTOS ANTROPOFÁGICOS ENTRE MPB E DANÇA: POSSÍVEIS RELAÇÕES INTERTEXTUAIS
}

\author{
ANTHROPHOGICAL MOVEMENTS BETWEEN MPB \\ AND DANCE: POSSIBLE INTERTEXTUAL RELATIONS
}

\author{
Taís Chaves Prestes*
}

RESUmo: Este artigo tem como propósito investigar os estudos intertextuais e suas possibilidades de articulação entre distintas materialidades. Para tanto, utiliza do conceito de Antropofagia (1928), advindo do movimento Antropofágico, conduzido pelo literato Oswald de Andrade na primeira geração do Modernismo brasileiro. $O$ intuito é que tal conceito dê conta de mediar e realizar possíveis aproximações entre MPB, enquanto objeto literário, e a dança-teatro alemã do Wuppertal TanzTheater, fundado pela bailarina/coreógrafa Pina Bausch, quando subsidiados do aporte literário de Carvalhal (1991). O corpus investigado são as músicas populares brasileiras utilizadas nos espetáculos da companhia, corroborando em suas diversas criações em dança. Diante desse cenário, buscamos investigar a intersecção entre eles, tanto para complexificar as categorias de entendimento, quanto para ampliar as possibilidades dialógicas entre as diferentes áreas.

Palavras-chave: antropofagia. dança-teatro. mpb.

Aвstract: This article aims to investigate intertextual studies and their possibilities for articulation between different materialities. For that, it uses the concept of Anthropophagy (1928), coming from the Anthropophagic movement, led by the literary Oswald de Andrade in the first generation of Brazilian Modernism. The intention is that this concept will be able to mediate and make possible approximations between MPB, as a literary object, and the German dance-theater of Wuppertal TanzTheater, founded by the dancer/ choreographer Pina Bausch, when subsidized by literary contribution of Carvalhal (1991). The investigated corpus is the Brazilian popular music used in the shows of the company, corroborating in its diverse dance creations, we seek to investigate the intersection between them, both to complex the categories of understanding, and to expand the dialogical possibilities between the different areas. KeYwords: anthropophagy. dance-theater. mpb.

\footnotetext{
"Doutoranda do PPGLetras da Universidade Federal de Pelotas (UFPel) na linha: Literatura, cultura e tradução. Professora substituta do curso de Dança licenciatura na mesma instituição e coordenadora do Projeto de Pesquisa LiteraCorpo. E-mail: taischavesprestes@hotmail.com.
} 


\section{Trama DE ESTÉTICAS TEXTUAIS DISTINTAS}

a palavra literária não é um ponto, um sentido fixo, mas um cruzamento de superficies textuais (KRISTEVA, 1969)

Ainda que o termo intertextualidade, dentro do aporte da Literatura Comparada, tenha sido cunhado pela russa Julia Kristeva na prestigiada revista TEL QUEL (Poética $n^{\circ} 27$ ) e toda a sua colaboração para a elucidação e aprofundamento sobre a temática e a relação entre textos seja fundamental e legítima, a intertextualidade acontece já há um bom tempo. Conforme apresentado em estudos anteriores em relação à investigação intertextual, desde a antiguidade, tanto Aristóteles quanto Platão já discorriam acerca de questões como a cópia, ineditismo, autoria, bem como o diálogo entre textos. Séculos mais tarde, na Idade Média, a relação com a comparação já era abordada (CORRALES, 2010, p. 4).

Além disso, é sabido que os estudos intertextos colaboram com discussões que vão além, utilizando temáticas as quais perpassam a área de Letras e outras, tais como psicanálise, música, teatro, geografia, antropologia, a estética da recepção, entre outras.

Entre os diversos estudos, largamente desenvolvidos, a pesquisadora Tiphaine Samoyault colabora para pensarmos sobre o assunto, trazendo questionamentos contundentes que ajudam a estabelecer os elementos constitutivos deste estudo: A intertextualidade deve ser compreendida antes de tudo como uma prática do sistema e da multiplicidade dos textos. De que maneira se analisam os movimentos e as operações da literatura em relação? Quais podem ser as diferentes etapas da análise? (SAMOYAULT, 2008, p. 43). Problematizações como estas sugerem percebermos tessituras possíveis de ocorrer em uma investigação intertextual, assimilando suas capacidades no que tange o destrinchar de fronteiras entre as diversas áreas, assim como sua potência de criação e pesquisa.

Inserida na Literatura Comparada, a Intertextualidade acaba por formar um grande mosaico nos estudos, sendo assim ela se mostra subversiva, pois seus contornos são maleáveis, elásticos e empáticos. Ela tende a ressignificar a relação de câmbio entre os elementos dos textos, aumentando a possibilidade referencial, interpretativa e estética oferecida ao leitor. Além disso, a intertextualidade reescreve novas rotas e amplia perspectivas quando mescla conhecimentos antes impensados enquanto junção de viabilidades. Mexe, portanto, com questões da memória, pois retoma marcas do texto primeiro, articulando-as com o texto segundo, reconstituindo e atualizando narrativas, conforme elucida Samoyault:

Ela exprime, movimentando sua memória e a inscrevendo nos textos por meio de um certo número de procedimentos de retomadas, de lembranças e de re-escrituras cujo trabalho faz reaparecer o intertexto. Ela mostra assim suacapacidade de se constituir em suma ou em 
biblioteca e de sugerir o imaginário que ela própria tem de si. Fazendo da intertextualidade a memória da literatura, propõe-se uma poética inseparável de uma hermenêutica: trata-sede ver e de compreender do que ela procede, sem separar esse aspecto das modalidades concretas de sua inscrição. (SAMOYAULT, 2008, p. 43)

No trecho supracitado, percebemos que a prática intertextual, muito mais do que um fim para os estudos literários, pressupõe um meio de dilatar as pesquisas que dela se utilizam, bem como estender o capital cultural tanto do investigador quanto do leitor. Assim sendo, a familiarização com os materiais selecionados acontece mais do que na pré-escolha de estudo, mas no seu intercurso, conforme for evidenciando seus possíveis contrastes, sobreposições e temáticas que, antes intercalados, agora apresentam um conjunto promissor. Posto isso, podemos compreender que o movimento de retirar e acrescentar os elementos que mais lhe convirem dos textos, a fim de formar um terceiro material, é uma descoberta constante e gradual.

Já no que tange à articulação entre as artes, neste campo, testemunhamos que a mesma tem crescido de maneira significativa. Diante de tal compreensão, a especialista Tânia Carvalhal elucida:

As relações entre a literatura e as outras artes encontram no campo dos estudos semiológicos, nas relações que os sistemas sígnicos travam entre eles, novas possibilidades de compreensão para essas correspondências. Embora os comparativistas tradicionais não incluam no campo de atuação da literatura comparada a relação entre literatura e outras artes, situando-a no âmbito geral da história da cultura, os comparativistas americanos a incorporam às suas preocupações (CARVALHAL, 2006, p. 50).

Sendo esta preocupação legítima e necessária, consideramos que esta maneira de imbricar saberes faz-se interessante, podendo vir a colaborar com os estudos das áreas previamente elencadas. Trata-se de explorar criticamente os dois textos, ver de que maneira eles se misturam e, a partir daí, como, repetindo-o, o segundo texto "inventa" o primeiro. Dessa forma ele o redescobre, dando-lhe outros significados já não possíveis nele mesmo (CARVALHAL, 2006, p. 58). De maneira didática e objetiva, a autora explana o movimento que se efetua na prática intertextual quando no momento da sua exploração.

Compreendida esta parte, na presente pesquisa, a proposta é observarmos como uma companhia de dança contemporânea pode colaborar com as transformações literárias, construindo relações intertextuais promissoras, as quais fogem do senso comum. Aqui, os textos com materialidades distintas apresentam possibilidades instigantes quando intencionalmente interseccionados. 


\section{ApRESENTANDO: DANÇA-TEATRO}

A bailarina contemporânea Philippina Bausch, mais conhecida como Pina Bausch, teve como característica em sua companhia Wuppertal Tanztheater o trabalho de criação em Dança-Teatro, recorte da dança contemporânea que une elementos da dança e do teatro, constituindo uma única linguagem híbrida. A singularidade de seu trabalho é ser herdeirada dança expressionista alemã de Kurt Jooss, o qual acreditava em uma arte que tivesse um olhar diverso; portanto, seu trabalho possuía a junção de inúmeras linguagens, livre de qualquer tipo de hierarquia. Retomando as criações da companhia de Pina o grupo se utiliza das próprias histórias de vida dos bailarinos para iniciar os processos coreográficos, além disso, mescla cinema, antropologia, geografia, filosofia, psicologia e mais uma gama de áreas de conhecimentos nas temáticas elencadas para seus trabalhos.

É válido ressaltar que as criações da companhia aconteciam em um processo muito intuitivo e grupal. Como o virtuosismo não é elemento predominante e todas as cenas se constituem coletivamente, a descoberta e como tendem a emergir os detalhes da cena costumam ser de cunho muito mais afetivo e sensitivo. Segundo a pesquisadora Claudia Galhós, em ensaio biográfico desenvolvido sobre Pina: "até ao final, foi sempre esse o caminho do seu gesto criador: nasce no interior e só depois emerge à superfície da pele” (GALHÓS, 2010, p. 27).

Em alguns de seus espetáculos, a companhia alemã utilizou músicas brasileiras a fim de enriquecer o repertório estético, contrastando culturas. A música, que se distingue da literatura por uma maior complexidade de seu discurso, autoriza transformações de duas naturezas: no texto da partitura, mas também na interpretação pela execução (SAMOYAULT, 2008, p. 43). A MPB (música popular brasileira), além de ganhar visibilidade e perpassar pelos corpos em movimento, colaborou com a ideia de multiplicidade e originalidade tão próprias na constituição deste grupo. Em 1980, em apresentação no Brasil por quatro cidades, Pina, além de afinar relações com a cultura local, inspira-se para produções futuras e, em 1982, retorna ao país com peças cravejadas de canções brasileiras (CYPRIANO, 2018, p. 89). Além da peça Valsas (1982), considerada pela coreógrafa uma peça sobre o Brasil, ao longo dos anos a companhia alemã desenvolve trabalhos diversos contando com o universo poético contido nas canções da MPB. Segundo pesquisa desenvolvida por Cypriano:

Também em 1982, a coreógrafa cria Cravos, uma de suas peças mais reencenadas desde então, com três canções brasileiras: Pastorinhas, de Noel Rosa e João de Barro, Dama das Camélias, de Alcyr Pires Vermelho e João de Barro, e Malmequer, de Cristóvão de Alencar e Newton Teixeira [...]. Desde então a música brasileira é utilizada constantemente pela coreógrafa. Já se ouviu $S$ Wonderful, na voz de João Gilberto, em O Dido, de 1999; Alô, alô, marciano, com Elis Regina, em Só você [Nur Du], de 1996; e Caetano Veloso, com Que não se vê, em Terra de prados [Wiesenland], 
de 2000, entre outras. Na peça criada em Wuppertal fora do sistema de coproduções, em 2002, Caetano ressurge com Leãozinho. (CYPRIANO, 2018, p. 89-90)

Este universo de possibilidades nas produções, apropriações e investigações incessantes em seus espetáculos evidenciam a perspectiva de emaranhados legítimos contidos nas criações filosoficamente dançadas pela companhia de Bausch. "Com isso, a coreógrafa apropria-se antropofagicamente das variações culturais, e confere às suas criações um poderoso caráter transcultural" (CYPRIANO, 2018, p. 34). A lógica antropofágica parece acolher de maneira apropriada a intenção que buscamos evidenciar nesta pesquisa: o cuidado e refinamento na articulação entre os textos de distintas materialidades, descobrindo suas especificidades a fim de trabalhar suas potencialidades quando combinados destacam características muito afins com o conceito literário citado, já que se utiliza da minúcia, tato, mas principalmente feeling para as escolhas que, de fato, estarão presentes no palco em determinado momento. Conforme esclarece Galhós nas práticas processuais da companhia:

As relações em toda a sua expressão surgem inevitavelmente como matéria de conteúdo, composição e organização tumultuosa da forma. Muitas vezes, em pleno processo criativo, ela dizia que não sabia o que procurava, mas que, quando o encontrava, o sentia no ventre [...] (GALHÓS, 2010, p. 31).

Este trecho mostra a importância da falta de pressa, do debruçar-se em algo para que possa desbloquear caminhos rompendo possíveis fronteiras existentes. O produzir por produzir nunca foi relevante na companhia de Bausch e, por conta desse ritmo muito próprio de criar, o grupo apresenta um perfil excêntrico no que oferece para o seu público. De maneira interessante fica ressaltada ali a resolução de problemas em dança, os quais, curiosamente podem ser resolvidos de maneira outra em uma próxima apresentação, inclusive por outro conjunto de materialidades e influências.

\section{SOBRE ANTROPOFAGIA}

"Tupi or not Tupi, that is the question"

(Oswald de Andrade, 1928)

Só a ANTROPOFAGIA nos une. Socialmente. Economicamente. Filosoficamente (1976), inicia dessa maneira Oswald de Andrade o seu Manifesto Antropófago em 1928, aliado a Raul Bopp e Tarsila do Amaral, eles formaram o grupo chamado: Antropofágico. A herança deixada pelos modernistas brasileiros, logo em sua $1^{a}$ fase, conhecida como fase da destruição, tinha a intenção de misturar culturas, sendo lançada na Semana de Arte Moderna de 22 na cidade 
de São Paulo. De grande inspiração criativa para os artistas modernistas, lançou base para uma cultura nacional, passando ferozmente pelo movimento tropicalista, respingando e se atualizando na contemporaneidade. A Abapuru (nome de origem Tupi que significa Homem que come), obra de arte criada por Tarsila do Amaral e dada de presente a Oswald de Andrade, é compreendida como o principal símbolo do manifesto antropofágico brasileiro, pois une a cultura brasileira (cores, por exemplo) com a estrangeira (formas, traços e técnica). Além disso, é importante que estejamos atentos a outras fontes que já costumavam se debruçar na temática canibal. Segundo o que elucida o espaço de Arte e investigação online Enciclopédia Itaú Cultural:

A temática do canibalismo comparece em autores tão diversos quanto o poeta futurista Filippo Marinetti, o pintor surrealista Francis Picabia, que edita sua revista Cannibale em 1920, o poeta Blaise Cendrars, entre outros. Certamente o autor dialoga com o movimento europeu, mas confere a imagem originalidade quando a transforma em metáfora de um procedimento criativo, ativo e crítico, gerador de uma arte brasileira moderna e autônoma. (ENCICLOPÉDIA ITAÚ CULTURAL, 2017).

Embora haja uma gama de obras deste período, tais como: Ovo [Urutu] (AMARAL, 1928) e Antropofagia (AMARAL, 1929) e A Negra (AMARAL, 1923), todas criações de Tarsila, a Abaporu (AMARAL, 1928) foi precursora e até os dias atuais é a mais lembrada enquanto marco no movimento brasileiro. O conceito de antropofagia destaca o ritual canibal como algo potente no momento do processo de criação: comer o que vem do outro, deglutir e regurgitar formando algo novo. Este foi um dos mecanismos utilizados pelos artistas do movimento tropicalista, por exemplo, quando retomaram referências modernistas levando em conta o canibalismo cultural para novas fazeduras em arte. Bem como explica o artista Caetano Veloso em sua obra Verdade Tropical (VELOSO, 1997):

O segundo manifesto, o Antropófago, desenvolve e explicita a metáfora da devoração. Nós, brasileiros, não deveríamos imitar e sim devorar a informação nova, viesse de onde viesse, ou, nas palavras de Haroldo de Campos, assimilar sob espécie brasileira a experiência estrangeira e reinventá-la em termos nossos (VELOSO, 1997, p. 182).

A partir de tal excerto, percebemos o esclarecimento de um conceito advindo da literatura, vivido e experienciado pelo próprio artista brasileiro. Essa transmutação que se vive por meio da vivência antropofágica permite não somente a reinvenção de uma obra, mas a reinvenção de si enquanto corpo criador e movente. Sendo assim, o fato de alimentá-lo de muitas fontes passa a ser experimental, bem como passa a ser a própria obra. A ideia de antropofagia desenha e explora mapas em caminhos desconhecidos, deixando pegadas por onde passa. Diante disso, há vários aspectos em que o objeto literário, aqui elencado, é capaz 
de se desdobrar, não há um padrão, há sim, uma vontade disponível para experimentar: só me interessa o que não é meu. Lei do homem. Lei do Antropófago (ANDRADE, 1976). Fosse ele próprio como produtor de exportação ou um produtor artístico basicamente característico do solo brasileiro, entendemo-lo como um todo único e autêntico, já que a liberdade de experimentar, legitima a prática que elege e escolhe, segundo o que Tania Carvalhal elucida:

A proposta antropofágica é, sem dúvida, fascinante. Mas dela o que parece ser mais rentável para os estudos comparados não é apenas a reversibilidade do processo; portanto, não é a devoração (assimilação) vista no seu sentido mais superficial, mas compreendida no seu caráter seletivo, como capacidade críticade selecionar do alheio o que interessa (CARVALHAL, 2006, p. 81).

Neste ínterim, o artista-pesquisador passa a ser corpo escritor do novo que advém, em parte, do outro. Vale ressaltar que o corpo performático, seja ele da literatura, música, dança, teatro, circo, fotografia, enfim qual linguagem criativa for, é dono de um vocábulo que se dá de maneira provisória, efêmera, aberto a transmutar-se. Além disso, o conceito antropofágico passou a ser explorado em uma proporção global, visto que abrange, além das variadas linguagens artísticas possíveis, também desmembra culturas, regiões e os mais distintos campos do saber, colocando em evidência como vem sendo ampliado este "conceito guarda-chuva", muito próprio do criar artístico literário brasileiro, bem como colabora a professora- pesquisadora que se debruça no assunto, Mônica Dantas:

As metáforas de consumo de carne humana são talvez metáforas violentas. Mas elas podem ser uma das estratégias de afirmação cultural, artística e política em países de economia periférica. Penso também que a antropofagia se distingue das noções de multiculturalismo, impureza, hibridização, porque, menos demagógica e consensual, oferece a experiência de uma violência transformada. Se em geral, autores estrangeiros que escrevem sobre arte e cultura brasileiras têm a tendência a interpretar a maior parte da nossa produção como herdeira da antropofagia, também é verdade que ela vem sendo utilizada para pensar a arte atual num contexto de globalização, inspirando a mimeis cultural de Jeudi (1999) e a antropofagia no ciberespaço de Schütz (2000) (DANTAS, 2007, p. 2).

Além de todos os aspectos apresentados pela pesquisadora, faz-se míster abordarmos uma outra perspectiva, ainda menos romântica, por assim dizer, da noção de antropofagia, a que parte do ponto de vista da colonização. Com cada vez mais frequência são destacadas problematizações que discutem o processo de colonização, a figura do indígena na contemporaneidade, bem como estratégias ou modos para uma descolonização efetiva. A ideia repetida de antropofagia brasileira para formar uma identidade própria daqui, pode parecer estar em 
um invólucro paradoxal, uma vez que tal formação identitária, além de se valer de técnicas e costumes europeus, é validada e reforçada em fluxo contínuo por seus descendentes, amenizando possíveis concepções nacionais "legítimas". Segundo a pesquisadora e ativista das causas indígenas:

[...] mesmo que o Brasil fosse descolonizado, os efeitos da colonização permaneceriam para sempre. Um exemplo é o uso do conceito de canibalismo, desenvolvido no Manifesto Antropofágico de Oswald de Andrade, um euro-brasileiro de uma família eminente (ALVES, 2018, p. 34).

Neste excerto fica evidente o quanto ainda estamos tateando maneiras de consolidar nosso próprio modelo de descolonização. O conceito de canibalismo não está integralmente desvinculado da estrutura de poder europeu (sejam político, econômico, social ou artístico) como se corre o risco de pensar. Sendo assim, é importante considerar a importância de descentralizar o europeu da história advinda do Manifesto literário proposto por Oswald. Prosseguindo a problematização, a pesquisadora propõe questionamentos que causam fissuras no pensar a antropofagia no Brasil no que tange impugnações referentes aos povos indígenas:

E o que aconteceria em países como o Brasil, onde os não-indígenas são uma abrangente maioria e os indígenas estão em clara minoria? Os não-indígenas, como é o caso, sentem-se muito confortáveis no pressuposto de que a colonização terminou. Sendo este o caso, o que dizer aos indígenas? Que não existem? Que não contam? Que devem progredir? Como essa situação colonial poderia ser ultrapassada através de um decreto unilateral, determinado pelo colonizador? Através da negação dos indígenas colonizados? (ALVES, 2018, p. 33-34)

Tais questionamentos envolvendo indígenas e não-indígenas abordam distintos prismas de um mesmo pressuposto. É imprescindível a compreensão do que acontece em tais perspectivas a fim de não ficarmos apartados dos movimentos que carregam confrontos os quais versam sobre sua perda da liberdade criando ou resistindo novas práticas artísticas assombradas por seus reflexos históricos.

A devoração cultural, enquanto movimento estratégico fortalecedor do artista, incorpora sorvendo a qualidade de outrem, mas principalmente saboreando a consolidação de si enquanto corpo-experiência. Essa afirmação legitimada da cultura brasileira atravessa constante transição e atualização do movimento primitivo impregnado nos corpos uma vez colonizados. A perspectiva de fundir culturas além de criar, afronta formulações teóricas remetendo a importância de emergir algo genuinamente brasileiro, exclusivamente plástico, o qual, por mais que venha a "se aproveitar" da estrangeiridade, ativa a necessidade da crítica ao eurocentrismo, enquanto questão de sobrevivência da espécie. Diante de tais elucidações 
e a fim de apurar a aproximação ao conceito antropofágico é provocada a compreensão, não somente do termo, mas também do aporte que cerca e colabora com este estudo. Assim compreendida, a literatura comparada é uma forma específica de interrogar os textos literários na sua interação com outros textos, literários ou não, e outras formas de expressão cultural e artística (CARVALHAL, 2006, p. 74).

\section{MPB, DANÇA-TEATRO E UM MOVIMENTO ANTROPOFÁGICO IMPLACÁVEL:}

tinham me anunciado um show de idéias cromadas e eu encontrava a vida

(VELOSO, 2000)

Debruçando-nos, especialmente, no estudo das inter-relações, dos contágios, das imbricações e dos atritos entre Literatura e Dança por meio do aporte da intertextualidade e suas possibilidades que, cada vez mais, convergem entre si, também geramos processos discursivos cada vez mais complexos e entregues. Este estudo focaliza-se em pensarmos sobre pertinência da mescla das áreas de conhecimentos supracitadas, quando na promoção de uma pesquisa que colabore nos campos das Letras e Artes, contemplando os estudos intertextos.

Como já citado anteriormente, a relação da companhia alemã de Pina Bausch com a música brasileira foi estreita, após sua primeira visita ao país. A poesia, a batida, o balanço, o fluxo criativo e a vitalidade presentes nas canções genuinamente próprias daqui, chamaram atenção enquanto elemento potente para contribuir para suas criações estéticas cuidadosamente concebidas. Existe na gama de versos contidos nas canções a consciência do exercer poético, aliado ao comprometimento social e por que não dizer com o cotidiano do povo brasileiro? As características modernas que flertam com o passado, o ontem, a tradição, de alguma maneira,é exatamente esse "flerte" que os constitui. Segundo o letrista Carlos Rennó:

A música popular - ou talvez seja mais exato dizer "a canção popular" - que ganhou imensa difusão no século XX, tornando-se uma expressão do espírito dos tempos modernos, e que continua florescendo com grande esplendor [...] no Brasil, vem realizando, por sua vez, em seus momentos culminantes, uma espécie de retomada, no plano da produção artística de consumo, da arte poética [...]. (RENNÓ, 2003, p. 52).

Diante da lírica e poética moventes, tão características deste perfil musical, compreendemos que as canções imprimem uma variação peculiar. Isso fica evidente na presença frequente em festivais e eventos exibidos no rádio e TV, por exemplo, em pleno período de ditadura, alastrando-se em território nacional, sendo propagado enquanto perfil artístico representativamente brasileiro. $O$ país reconhece na música lugar possível de manifestação social, força e esperança, bem como observamos no trecho abaixo: 
Inúmeras foram as letras de caráter crítico que tiveram seus textos adaptados e reformulados em função do espaço sócio-político, sobretudo em tempos de repressão. Compositores como Chico Buarque de Holanda, Gilberto Gil, Geraldo Vandré e inclusive, Caetano Veloso, tiveram de adequar seus textos a momentos de extrema restrição quanto à liberdade de preservar versos cujo papel sociológico (externo) une-se ao literário através dos recursos estilísticos (SANTOS, 2008, p. 26).

No período que compreende a Tropicália, os artistas retomaram o conceito antropofagia como forma de estabelecer seu perfil identitário as criações próprias daquela época, não somente na fala, na palavra estetizada, no verso velado de problematização, reclame e resistência, mas também nos corpos que se colocavam à prova durante todo o tempo de exposição artística. Foi esse perfil apanhado do qual a companhia de Pina Bausch se apropria em seus espetáculos. No espetáculo Água (2001) há uma relevante fração da MPB contida e incorporada, já que o espetáculo em si, refere-se diretamente à cultura nacional, ficando, portanto, notória a apropriação musical e cultural que constrói. O esquema de retroalimentação opera no fazer em dança, sendo potencializado pela música brasileira que, no espaço do palco, já se constitui de outras forças:

Começa a tocar Samba da benção, de Baden Powell e Vinícius de Moraes, na voz de Bebel Gilberto. Na Young entra com algo amarrado na ponta de um fio, introduz isso na boca de Jorge, sentado na primeira fila da plateia e grita "Puxa, puxa!". Regina, que estava no fundo do palco, puxa a vara de pescar, fisgando assim o rapaz. Christiana é cumprimentada pelos rapazes com dois beijinhos, nos seios e depois no rosto, citação debochada da forma de se cumprimentar no Rio de Janeiro (CYPRIANO, 2018, p. 109).

As aproximações propostas ressaltam a importância do experimento, da troca cultural, mas, sobretudo do estabelecimento de confiança, análise e reaproveitamento do que vem do outro. O novo aparece como combustível para impulsionar a tantos outros lugares e territórios de si ainda não invadidos. Podemos dizer que tivemos nesse movimento antropófago dançado nada menos do que palavras, corpos, vidas e vontades movidos e acometidos pelo desejo. Afinal, parece não haver nada mais excitante do que ser um corpo que se move desejoso de algo, caso contrário a estagnação seria certeira.

Os caminhos agora outros são borrados por experiências que o modificaram ao invés de servir como ilustração para ideias supostamente indiscutíveis, instigavam a imaginação a uma crítica da nacionalidade, da história e da linguagem (VELOSO, 1997, p. 181). A dança da companhia alemã joga com as possibilidades de criação e reinvenção de si quando em experimento e descobrimento dos fazeres em arte. Eles se constroem no caminho e nos atravessamentos vividos em corpos dilatados de aspiração pelo outro, pelo o que é do outro e do 
que deixou de ser. $O$ ato de dançar, em termos gerais, é o de estabelecer relações testadas pelo corpo em uma situação, em termos de outra, produzindo, neste sentido, novas possibilidades de movimento e conceituação (GREINER, 2005, p. 132).

As inquietações são constantes na companhia, fato que, antropofagicamente é instigante, ao passo que os bailarinos do grupo advêm de diversos países do mundo. Esse engolir o que vem do outro capta uma distinção infinita de significados, sendo regurgitados numa gama enorme de gostos, movimentos, vozes e sentidos. Toda essa construção coletiva se mostra intencional e, ainda que nunca se saiba o resultado do bolo alimentar a ser produzido, nenhuma devoração é inofensiva, segundo o que nos instrui Carvalhal:

Toda repetição está carregada de uma intencionalidade certa: quer dar continuidade ou quer modificar, quer subverter, enfim, quer atuar com relação ao texto antecessor. A verdade é que a repetição, quando acontece, sacode a poeira do texto anterior, atualiza-o, renova-o e (por que não dizê-lo?) o reinventa (1991, p. 53).

Conforme elucida o trecho supracitado, a articulação entre as distintas referências artísticas, neste caso MPB e Dança, se fortalece quando em relação, transformando materialidades e recriando textos. Incorporar os versos das canções brasileiras, refazendo-os em outros tempos, bem como em outros versos, põe à prova o desembaraço e a constância de um exercício criativo ininterruptamente recriado e cuidadosamente absorvido. Segundo Greiner a recepção de novos elementos e as possíveis transformações se dão de maneira simultâneas:

Em termos de percepção, aos poucos torna-se claro que no momento em que a informação vem de fora e as sensações são processadas no organismo, colocam-se em relação. É quando o processo imaginativo se desenvolve. Assim, a história do corpo em movimento é também a história do movimento imaginado que se corporifica em ação (2005, p. 64).

Esse feito é perceptível na coautoria efetuada em canção-dança-músico-letrista- bailarinos-intérpretes-plateia. "Em outra cena, Regina canta Milagre, de Dorival Caymmi, ao mesmo tempo que massageia a perna com um aparelho de fisioterapia" (CYPRIANO, 2018, p. 107). É envolvente perceber que as características desafiadoras, corajosas e com caráter de manifestação presentes na MPB também contemplam as peças bauschinianas em termos de intensidade e irreverência, já que "a MPB é um 'complexo cultural', e não apenas um gênero musical específico, em razão de sua duração e diversidade estética” (ENCICLOPÉDIA ITAÚ CULTURAL, 2017).

Como destaca a pesquisadora Christhine Greiner, em sua obra $O$ corpo: Pistas para estudos indisciplinares (2005), "um corpo é inseparável da sua própria história no fluxo da vida" (p. 20, 2005); logo, entende-se a impossibilidade de criar e experimentar sem destacarmos 
o papel e as transformações em determinados contextos históricos. Neste caso, o manifesto antropófago, que nos instigou a discorrer sobre este campo minado de peculiaridades e modos de fazer tão possíveis no processo antropofágico que se mostra intertextual por si, excêntrico como música de resistência, corajoso como corpo movente que se põe à prova do desconhecido, ambos compartilham da mesma fome: criar. Em suma, eu me comovia e me esquecia de mim e reencontrava lugares do espírito que aos poucos reconhecia e era levado a outros lugares que desconhecia até então e que me faziam entender melhor os antigos lugares (VELOSO, 2000).

\section{CoNSIDERAÇõES FINAIS}

As inquietações entre canção e dança se fazem necessárias fundamentando e sensibilizando esta pesquisa no interesse de procurar viabilizar a amplitude do universo intertextual, contextualizando-os com referências artísticas, experiências estéticas e histórias que, não somente se inter-relacionam, mas se retroalimentam.

A noção de Antropofagia, aqui abordada para desenvolver a aproximação intertextual, evidenciou a potência que o conceito carrega e possibilita, expandindo a capacidade discursiva da temática proposta previamente.

Embora unir música e dança pareça algo evidente, a Antropofagia redimensionou as capacidades da pesquisa, mostrando questões históricas, culturais, estilísticas, estéticas diretamente imbricadas e recriadas a partir de outras materialidades.

Como salientado por Claus Clüver, "esse fenômeno é tão comum que já declarei em outro lugar que a intertextualidade sempre significa também intermidialidade" (CLUVER, 2006, p. 14), usando "intertextualidade" em referência a todos os tipos de texto; e uma forma condensada de dizer que entre os "intertextos" de qualquer texto (em qualquer mídia) sempre há referências (citações e alusões) a aspectos e textos em outras mídias.

Embora seja desafiador colocar o corpo à prova, deixando-o em evidência, aqui, ele se mostrou ser corpo escritor redigindo seu próprio texto por meio dos exemplos da companhia de dança-teatro alemã. Ainda que a música seja parceira incontestável das coreografias desde há muitos anos, é curioso perceber a forma com que outros elementos ajudam na construção das cenas dos espetáculos. O virtuosismo passa a ser secundário e o experimento genuíno através da história do outro mostra-se o verdadeiro ponto de encontro.

A cultura é retomada, o passado é transformado, lembranças são analisadas e meticulosamente pinçadas. O simples é filosoficamente complexo, sobretudo quando coloca a público. Há um certo de ironia, brincadeira e de destrinchar o que a massa acredita saber, tanto na MPB quanto na dança. O corpo se torna um espaço de resistência frente às diversidades e nega o caráter supra-humano em que a técnica, em geral, busca formatá-lo. Assim, corpo e sentimentos representam no palco uma unidade; ambos são a expressão da 
fragilidade da existência humana. (CYPRIANO, 2018, p. 29). Ou seja: ideia contrária do que o virtuosismo técnico procura passar e isso é válido para qualquer versão corporal: desde o escrito até o bailarino.

A relevância deste campo de estudo está em reforçar a articulação entre os distintos saberes e textos, independentemente de suas materialidades e possibilitar o convite à descoberta de possibilidades para troca de experiência singulares. Fica indubitável a força que passa a ter o artista que se dispõe à troca e se coloca à prova para enxergar uma outra perspectiva de uma obra que uma vez foi dita, sua.

\section{REFERÊNCIAS}

ALVES, Maria Thereza. Canibalismo no Brasil desde 1500. Revista Muiraquitã [Rio Branco], ano 6, n. 1, p. 26-40, jun. 2018.

AMARAL, Tarsila do. Ovo [Urutu]. 1928. Óleo sobre tela, 72,50 cm x 60,50 cm.

AMARAL, Tarsila do. Antropofagia. 1929. Óleo sobre tela, $126 \mathrm{~cm}$ x $142 \mathrm{~cm}$.

AMARAL, Tarsila do. A Negra.1923. Óleo sobre tela, $100 \mathrm{~cm}$ x $80 \mathrm{~cm}$.

AMARAL, Tarsila do. Abaporu.1928. Óleo sobre tela, $126 \mathrm{~cm}$ x $142 \mathrm{~cm}$.

ANTROPOFAGIA. In: ENCICLOPÉDIA Itaú Cultural de Arte e Cultura Brasileiras. São Paulo: Itaú Cultural, 2021. Disponível em: http://enciclopedia.itaucultural.org.br/termo74/antropofagia. Acesso em: 18 fev. 2021.

CARVALHAL, Tânia Franco. Literatura Comparada. São Paulo: Ática, 1991.

CARVALHAL, Tânia Franco. Intertextualidade: a migração de um conceito. Via Atlântica [São Paulo], n. 9, p. 125-136, jun, 2006.

CORRALES, Luciano. A intertextualidade e suas origens. In: Semana de Letras. 10, 2010, Porto Alegre. Anais.... Porto Alegre: PUCRS, 2010, p. 1-12.

CLUVER, Claus. Da Transposição intersemiótica. In: Poética do Visível: Ensaios sobre a escrita e a imagem. ARBEX, Márcia. Belo Horizonte: Programa de Pós-Graduação em Letras: Estudos literários, Faculdade de Letras da UFMG, 2006.

CYPRIANO, Fábio. PINA BAUSCH. São Paulo: SESI-SP Editora, 2018.

DANTAS, Mônica. Corpos Antropofágicos em Liquidação Total. Portal ABRACE, 2007.

GALHÓS, Claudia. Pina Bausch: Sentir mais. Lisboa: Dom Quixote, 2010.

GREINER, Cristine. O corpo. Pistas para estudos indisciplinares. São Paulo: Annablume, 2005. 
KRISTEVA, Júlia. Introdução à Seminálise. São Paulo: Debates, 1969. MÚSICA Popular Brasileira. In: ENCICLOPÉDIA Itaú Cultural de Arte e Cultura Brasileiras. São Paulo: Itaú Cultural, 2021. Disponível em: http://enciclopedia.itaucultural.org.br/termo3746/musica-popularbrasileira. Acesso em: 20 fev. 2021.

OLIVEIRA, Solange Ribeiro de. Literatura e música: trânsitos e traduções culturais. Revista Brasileira de Literatura Comparada, v. 5, n. 5, p. 93-100, 2000.

RENNÓ, Carlos. Poesia literária e poesia de música: convergências. In: Literatura e música. OLIVEIRA, Solange Ribeiro et al. São Paulo: Editora Senac São Paulo: Instituto Itaú Cultural, 2003, p. 49-71.

SANTOS. Max Jeferson dos. A poética contemporânea de Caetano Veloso por meio da leitura de quatro canções. Programa de Pós Graduação de Letras e Linguística. Faculdade de Letras, Faculdade Federal de Alagoas, Maceió, 2008, 122 p.

SAMOYAULT, Tiphaine. A intertextualidade. São Paulo: Editora Hucitec, São Paulo, 2008.

VELOSO, Caetano. Verdade Tropical. São Paulo: Companhia das Letras, 1997.

VELOSO, Caetano. Aquela coisa toda. Jornal Folha de São Paulo, 27 de agosto de 2000. Disponível em: https://www1.folha.uol.com.br/fsp/mais/fs2708200009.htm. Acesso em: 20 fev. 2021.

Recebido para publicação em: 1 ago. 2021. Aceito para publicação em: 24 out. 2021. 